\title{
Proposing Forgiveness Therapy for those in Prison: An Intervention Strategy for Reducing Anger and Promoting Psychological Health
}

Robert Enright ${ }^{1^{\star}}$, Tomaz Erzar ${ }^{2}$, Maria Gambaro ${ }^{3}$, Mary Cate Komoski ${ }^{4}$, Justin O’Boyle ${ }^{5}$, Gayle Reed ${ }^{6}$, Jacqueline Song ${ }^{7}$, Mark Teslik $^{5}$, Brooke Wollner ${ }^{4}$, Zhuojun $\mathrm{Yao}^{4}$ and Lifan $\mathrm{Yu}^{4}$

${ }^{1}$ Department of Educational Psychology, University of Wisconsin-Madison, Wisconsin, USA

${ }^{2}$ Department of Theology at the University of Ljubljana, Slovenia

${ }^{3}$ Columbia Correctional Institutions in Portage, Wisconsin, USA

${ }^{4}$ Department of Educational Psychology, University of Wisconsin-Madison, USA

${ }^{5}$ Wisconsin Department of Corrections chaplains, Columbia Correctional Institution, Columbia

${ }^{6}$ Private practioner and specialty in Forgiveness Therapy, Wisconsin. USA

${ }^{7}$ International Forgiveness Institute, Clinical psychology at the University of the Philippines-Diliman, Philippines

*Corresponding author: Robert Enright, Department of Educational Psychology, University of Wisconsin-Madison, Wisconsin, USA, Tel: 608-262-0835; E-mail: rd.enright@yahoo.com

Received date: December 23, 2016; Accepted date: December 27, 2016; Published date: December 30, 2016

Copyright: (C) 2016 Enright R, et al. This is an open-access article distributed under the terms of the Creative Commons Attribution License, which permits unrestricted use, distribution, and reproduction in any medium, provided the original author and source are credited.

\begin{abstract}
We propose a novel approach to corrections, both in maximum security prisons for adults and juvenile detention centers for adolescents. It is our hypothesis that unjust treatment from others can lead to inner pain, which can lead to anger. Unresolved anger can deepen and linger, turning to what we call excessive anger, compromising one's psychological health and behavior. Excessive anger can turn to rage (very intense, potentially violent anger) which can fuel crime, a lack of cooperation within the prison system, and increased recidivism rates. When the excessive anger is caused by unjust behavior from others, prior to a person's crime, conviction, and imprisonment, then we can reduce and even eliminate the excessive anger through the empirically-verified treatment of Forgiveness Therapy. It is rare, in our experience, for prison rehabilitation to have those in prison look backward, toward the injustices that happened to them prior to the crime. When they are given the chance to do this, they have the opportunity, perhaps for the first time, to confront the injustice and to heal from the pain and anger resulting from the unjust actions against them that might have happened years ago, even in childhood. Forgiveness Therapy may be one of the few existing mental health approaches which offer the opportunity to be free of excessive anger, perhaps for the first time in the person's life. Research on Forgiveness Therapy with an imprisoned sample of youth in Korea is described as are two individual cases of men within a maximum security facility.
\end{abstract}

Keywords Forgiveness therapy; Anger reduction; Resentment; Maximum security prisons; Juvenile detention

\section{Commentary}

We propose a new approach to corrections. With overcrowding in the prison system and with staffing less than optimal in the United States, the United Kingdom, and elsewhere [1-3], the presence of anger and other psychological problems is a very present and serious issue [4]. Moreover, it is our contention that the people imprisoned deserve to be regarded and treated as human beings with real needs for change and healing.

The Columbia Correctional Institution (a maximum security prison in Wisconsin) staff (Dr. Maria Gambaro, Chaplain Teslik, Chaplain O'Boyle) recently have been offering groups of men forgiveness interventions with the support of Dr. Robert Enright, University of Wisconsin-Madison, and the forgiveness research team in the Department of Educational Psychology. In the United States, maximum security is associated with heavy-duty perimeters, reinforced fences, and the people housed are considered to be the most violent, high-risk individuals requiring close control of their movements by officers compared with those in other prison levels such as medium and minimum security; juvenile facilities are reserved for those under age $18[5,6]$.

The anecdotal results have been encouraging. One person's behavior has become so improved that he has been able to come out of the secure portion of the maximum security prison and then move to a medium security facility. Six others also have had such improvements that they have qualified to move to medium security. The men themselves credit the forgiveness group experience for these positive outcomes. The Warden of Columbia Correctional Institution, Mr. Michael A Dittmann, has noted the positive reactions of those imprisoned and has invited the University of Wisconsin team to continue Forgiveness Therapy programs at his facility.

Forgiveness is a virtue $[7,8]$, like justice, patience, and kindness, in which a person has been treated unjustly by others, experiences pain because of this, and decides to reduce resentment and strives, over time, to offer goodness of some kind toward the offending person(s). To forgive is not to excuse, to necessarily reconcile, nor to ignore justice. Forgiveness and seeking fairness should occur together [9]. Forgiveness Therapy is the deliberate attempt to help clients to: a) understand what forgiveness is and is not; b) willingly choose to try forgiveness in the face of injustice; c) work through the process of forgiveness [10]; d) make possible the amelioration of excessive anger, 
caused by the pain of injustice, that can last for many years; and e) emotionally recover from the challenges of unjust treatment from others.

Research has shown that Forgiveness Therapy can substantially improve the emotional well-being of incest survivors [11] people in court-ordered drug rehabilitation [12], elderly cancer patients in hospice [13], emotionally-abused women [14], and others. There is a pilot study showing that patients in the forensics unit of a mental health institute also benefit from Forgiveness Therapy [15]. Justin O'Boyle, a chaplain at Columbia Correctional Institution, has stated, in a personal communication to Robert Enright, that in his experience very few therapeutic approaches work in corrections, and Forgiveness Therapy does work [16]. See Enright and Fitzgibbons [17] for a thorough review of the effectiveness of this therapeutic approach.

Our model for corrections is very simple, but literally never tried in corrections anywhere in the world to our knowledge: Unjust treatment from others can lead to inner pain, which can lead to anger. Unresolved anger can deepen and linger, turning to what we call excessive anger (unhealthy anger, deep resentment), defined as the kind of anger that compromising one's psychological health and behavior and can be associated with common psychiatric disorders such as generalized anxiety and major depressive disorders [17]. Excessive anger can turn to rage (an intensified anger that can lead to violence) and aggressive behavior toward others which can fuel crime, a lack of cooperation within the prison system, and increased recidivism rates. The excessive anger of those in prison must be healed if serious criminal behavior will be eradicated. Deeply emotionallyhurting people deeply hurt other people.

Forgiveness Therapy has been scientifically demonstrated to statistically eliminate excessive anger, associated with being treated unjustly by others, and related emotional challenges such as anxiety and depression [17]. Forgiveness, as a virtue to do no harm and to struggle to offer compassion to all, even to those who perpetrate injustice, has been shown to reverse the negative effects of unjust treatment and to restore a sense of well-being. To forgive is a statement that others' cruelty will not lead to the forgiver's being cruel, but instead to being a conduit for good.

If we can show that deeply hurting people are the ones who tend to perpetrate crime and if we can show dramatic changes in their emotional well-being through Forgiveness Therapy, then we will change the face of corrections, with an empirically-supported approach that can make prisons safer, lead to quicker and deeper rehabilitation, and likely reduce recidivism rates. After all, if we eliminate the excessive anger within people (and its intensified expression in rage and violence), then they are less likely to unleash that anger/rage/ violence onto others, as so often happens with crimes resulting in maximum security imprisonment.

The counselors and other mental health professionals at the institutions interested in implementing Forgiveness Therapy can be trained in how to implement this technique. We recommend such therapy for one hour per week for six months (24 sessions). The book, Forgiveness Is a Choice [18], is recommended for use by each counselor and each client. This is the manual used in the clinical trial already accomplished at the Columbia Correctional Institution and in many published randomized clinical trials as discussed above.

The gist of Forgiveness Therapy, as outlined in Forgiveness Is a Choice, is as follows. First, the client takes time to examine the injustices suffered and to have a period of anger and reflection. Next comes an exploration of what forgiveness is and is not to help the client to make an informed decision whether or not to pursue this form of therapy. After this comes what we call the work of forgiveness. This starts with cognitive exercises of trying to see the offending person as someone who possesses inherent (built-in) worth, not because of the unjust actions, but in spite of them. The point here is to expand one's story of whom the offending person is, as someone who is more than the behaviors perpetrated. From here, a sense of compassion can slowly begin to grow toward offending persons, who now are seen as vulnerable, perhaps confused, and even suffering persons. Such perspectives, which take time to develop, serve to diminish, even if slightly in the short-term, the presenting anger in the clients. From here, the counselor encourages the client to bear the pain of what happened. One cannot go back and reverse what happened. What can be reversed is one's reactions to that injustice. As the client decides to bear the pain, this means that there is a commitment not to bring on more pain to the one who initially caused that pain to the client. It is here that clients begin to see that they are stronger than they had thought. They begin to see that they can be conduits for good rather than as people who keep passing pain to others. From here, and only when the clients are ready, they are encouraged to give a virtuous gift to the one who acted unfairly. This could take the form of a civil greeting if they ever meet or even a kind word about that person to someone else. The client needs to see that the offer of forgiveness, in the face of injustice, is a heroic act. Who, then, is this client? Clients begin to form more positive identities toward themselves and emotional healing begins to take place.

\section{Initial Research Evidence}

Park et al. [19] investigated a randomized clinical trial to aid adolescent female aggressive victims in improve their psychological health as well as their school adjustment. Adolescent aggressive victims are defined as youth who demonstrate heightened levels of aggressive behavior and are frequently victimized by others. Forgiveness Therapy was tested against both an alternative skill streaming program and a no-treatment control group. Forty-eight female adolescent aggressive victims in Korea (age 12 years to 21 years) were recruited from a juvenile correctional facility and a middle school and were randomly assigned to one of the three groups. Both forgiveness and skill streaming interventions were implemented in a small-group format for 12 weeks each. Findings showed that the participants receiving Forgiveness Therapy reported statistically significant decreases in anger, hostile attribution, aggression, and delinquency at posttest and follow-up assessments. They further reported significant increases in empathy at posttest and follow-up as well as improved grades at the posttest.

\section{Individual Cases}

In September, 2016 an anonymous writer published an article in the prison newsletter, The Community (Wisconsin) [20]. It was published by a man who has received Forgiveness Therapy in a maximum security prison. He writes knowing that he is in prison for life. He tried many different mental health counseling programs "ad nauseum." He then states that when he entered the Forgiveness Therapy group, this was the best decision of his life when he accepted the challenge. We quote his experiences here:

This was the only program that ever asked me, "What happened to you to make you the way you are?" Everyone in the group had stories to tell about how they had been used, abused, and/or misused by those 
Citation: Enright R, Erzar T, Gambaro M, Komoski MC, O'Boyle J, et al. (2016) Proposing Forgiveness Therapy for those in Prison: An Intervention Strategy for Reducing Anger and Promoting Psychological Health. J Foren Psy 1: 116. doi:10.4172/2475-319X.1000116

Page 3 of 3

they trusted and/or looked up to. As we plodded through the first weeks some wanted to give up, some felt their stories too bad, and some just did not trust enough to share. As we progressed we became close like a family and knew the group was a safe place to deal with the anger and resentment that had plagued some of us over fifty years.

A second case is described in the Psychology Today site [21]. There a case is described in which Jonah (not his real name) was in mental health institutions and in maximum security prison for years. Only after experiencing Forgiveness Therapy did his anger subside to such a degree that he was moved from maximum to medium security prison. $\mathrm{He}$ is happy with his progress even though he remains in prison. "Forgiveness saved my life," was Jonah's message to the others imprisoned with him during a meeting in November, 2016.

\section{Future Directions}

We plan a series of studies for both males and females in maximum security prisons and juvenile detention centers. The first wave of studies, already commenced in Slovakia and the Midwestern United States, will be done to determine the extent to which people in these facilities: a) have been treated deeply unfairly prior to their crime and imprisonment; $b$ ) the degree to which the people show both excessive anger and unforgiveness toward those who acted unjustly; and c) the relationship among the excessive anger, forgiveness, and related emotions and moods such as anxiety and depression.

If the hypotheses are supported, we then plan a series of randomized experimental and control group trials, with counselors and chaplains within those systems first being trained in and then offering Forgiveness Therapy to the participants. Such interventions likely will need much time, perhaps as much as six-months of one hour per week in a group therapy format.

We anticipate significant reductions in anxiety, anger, and depression as well as increases in forgiving, hope, self-esteem, and empathy in future studies within maximum security adult prisons and juvenile detention centers. We then also would hope to see better relations with staff and others who share the prison environment. We are anticipating that these better relationships will include reductions in anger and violence. Given the positive results with such samples as incest survivors, people in drug rehabilitation, emotionally-abused women, juveniles in a detention center in Korea, and others with clinical compromise, the anticipated results seem warranted. Our aspiration is that Forgiveness Therapy will become a well-accepted protocol for people in prison and become available to all in the prison system who need it.

\section{References}

1. http://www.governing.com/gov-data/safety-justice/state-prison-capacityovercrowdingdata.html

2. https://www.theguardian.com/society/2016/may/18/prison-reform-notsolve-overcrowding-funding-problems-queens-speech

3. http://www.mirror.co.uk/news/world-news/worlds-most-overcrowdedjail-prisoners-9466942

4. Suter JM, Byrne MK, Byrne S, Howells K, Day A (2002) Anger in prisoners: women are different from men. Pers Individ Dif 32: 1087-1100.

5. http://www.crimemuseum.org/crime-library/types-of-prisons/

6. https://www.bop.gov/about/facilities/federal_prisons.jsp

7. Holmgren MR (1993) Forgiveness and the intrinsic value of persons. Am Phil Q 30: 341-352.

8. North J (1987) Wrongdoing and forgiveness. Philosophy 62: 499-508.

9. Enright RD, Fitzgibbons R (2015) Forgiveness therapy. Washington DC: APA Books, USA.

10. Enright RD (2001) Forgiveness is a choice. Washington, DC: APA Books.

11. Freedman SR, Enright RD (1996) Forgiveness as an intervention goal with incest survivors. J Consult Clin Psychol 64: 983-992.

12. Lin WF, Enright RD, Mack D, Krahn D, Baskin T (2004) Effects of forgiveness therapy on anger, mood, and vulnerability to substance use among inpatient substance- dependent clients. J Consult Clin Psychol 72: 1114-1121.

13. Hansen MJ, Enright RD, Baskin T, Klatt J (2009) A palliative care intervention in forgiveness therapy for elderly terminally ill cancer patients. J Palliat Care 25: 51-60.

14. Reed GL, Enright RD (2006) The effects of forgiveness therapy on depression, anxiety, and posttraumatic stress for women after spousal emotional abuse. J Consult Clin Psychol 74: 920-929.

15. Chapman RF, Maier GJ (2000) Forgiveness as an intervention for abused patients. The World of Forgiveness 3: 6-12.

16. O'Boyle J (2015) Personal communication by email to R Enright, August 10.

17. Enright RD, Fitzgibbons R (2015) Forgiveness therapy. Washington DC: APA Books, USA.

18. Enright RD (2001) Forgiveness is a choice. Washington DC: APA Books, USA.

19. Park JH, Enright RD, Essex MJ, Zahn-Waxler C, Klatt JS (2013) Forgiveness intervention for female South Korean adolescent aggressive victims. J Appl Dev Psychol 20: 393-402.

20. Anonymous (2016) Forgiveness is a choice. The Community (prison newsletter, Wisconsin), September, 6: 3 .

21. https://www.psychologytoday.com/blog/the-forgiving-life/201612/ forgiveness-saved-my-life 